\title{
Manifesting Social Responsibilities in Strategic Planning: A Question of Strategy Formulation
}

\author{
Ahmet Emre Demirci \\ Assoc.Prof. of Management and Strategy \\ Anadolu University, Faculty of Economics \& Administrative Sciences
}

\begin{abstract}
This study aims to analyze how public universities in Turkey conceptualize social responsibility and how they formulate their strategic plans in order to integrate their understanding of social responsibilities. In order to evaluate universities' formulation of social responsibility strategies, strategic plans of 99 out of 129 Turkish public universities were analyzed. Results of the content analysis have revealed that although the public universities in Turkey devote attention to social responsibility, they still must develop their understanding of social responsibilities in a multidimensional way. This is compounded by the lack of strategy development skills that in return restrain them to adopt an integrated approach to strategic management that involves a thorough analysis of internal and external factors and a careful formulation and implementation of strategies.
\end{abstract}

Keywords: Strategic planning, Strategy formulation, Social responsibility, Turkish public universities 